\title{
Chrysonilia sitophila: Growth on Different Culture Media and Sensitivity to Antifungals
}

\author{
Sorin RĂPUNTEAN ${ }^{1}$, Elena TĂLMACIU ${ }^{2}$, Mihaela COSTEA ${ }^{2}$, Flore CHIRILÁ $\breve{~}^{1}$, Zoltan BACÂRCEA ${ }^{1}$ and \\ Gheorghe RĂPUNTEAN ${ }^{1}$
}

${ }^{1}$ Department of Microbiology. University of Agricultural Science and Veterinary Medicine, Cluj-Napoca, Romania.

${ }^{2}$ The Institute for Diagnosis and Animal Health, Bucharest, Romania.

* corresponding author: sorin.rapuntean@gmail.com

Bulletin UASVM Veterinary Medicine 75(2)/2018

Print ISSN 1843-5270; Electronic ISSN 1843-5378

doi:10.15835/buasvmcn-vm: 2018.0024

\begin{abstract}
:
The species Chrysonilia sitophila has a cosmopolitan spread, living on dead or rotting plants, but it is also isolated from home and commercial spaces insulation. The aim of our study was to determining a growth pattern and assessing the susceptibility to different antifungals. The strain was isolated from the water of a trout breeding pool where high mortality due to Saprolegnia infection and various Gram negative and Gram positive bacteria occurred. On all used culture media (except for MacConkey), rapid growth is observed (tendency to spread over the entire surface of the plate in 36-48 hours). The isolated strain has been shown to be sensitive to ketoconazole, econazole, and miconazole; less sensitive to amphotericin B, but resistant to metronidazole, nystatin, griseofulvin and flucytosine. Chrysonilia sitophila can be grown easily, so it can also establish an antifungal sensitivity profile. Additional efforts should be made to study the pattern of susceptibility to different antifungals.
\end{abstract}

Keywords: Chrysonilia sitophila, cultivation, antifungal susceptibility.

\section{Introduction}

The genus Chrysonilia (von Arx1981), taxonomically framed in the family of Sordariaceae, includes three species: C. sitophila, C. crassa and C. tetrasperma. The species Chrysonilia sitophila (formerly Monilia sitophila), long known as the "red mold of bread", has a cosmopolitan, saprobiological spread, living on dead or rotting plants (21). It can also be found in homes, being isolated from carpets and dust from mattresses (20). From the external environment, it can reach different spaces and contaminate the bread, some pastries and various vegetables (hazelnuts, beans), fruits (apples, strawberries, raspberries) and meat products (Patel Sunil, 2008). High percentages of isolation are mentioned from the desert "Thai cassava", maize grains and peanuts of various origins (Pitt et Hocking, 2012). Bibliographic sources report an increasing number of isolates of $C$. sitophila from food, coffee, spoilage of bakery products (Berni et Scaramuzza, 2013) or wood processing plants (Monzónet all., 2009) but in recent years studies that investigate this microorganism have diminished.

Chrysonilia sitophila is considered a contaminant without pathogenicity but it can have implications in triggering asthmatic disease (occupational asthma) (Francuz et al., 2010), but does not appear, from the medical literature, to be a significant allergen.If it breaks the anatomical barriers, it is thought to have pathogenic implications (being isolated from the keratitis), and isolation from dialysis fluids could help this microorganism penetrate the body and eventually 
induce peritonitis in immunosuppressed individuals (Theodore et al., 1962; Naldy et al., 1999; Thomas et al., 2013).

Itcanbeadreadfulcontaminantwhenitspreads in laboratories and hospitals, because it can grow with great ease and thanks to the multiplication by spores it can easily contaminate many surfaces (Perkins et al., 2000) and workspaces used for various microbiological procedures.According to the authors' knowledge, animal diseases are not described so far, which highlights the potential for further investigations to find pathogenic or allergic effects.Also, bibliographic data on the susceptibility of these fungi to antifungals or other chemicals are absent. The aim of this study is to determine a growth pattern of Chrysonilia sitophila and assessing the susceptibility to different antifungal agents such as ketoconazole, econazole, miconazole, amphotericin B, metronidazole, nystatin, griseofulvin and flucytosine.

\section{Materials and methods}

The strain was isolated from the water of trout breeding pool, from Mureș county, Romania, where high mortality due to Saprolegnia and various Gram negative and Gram-positive bacterial infections occurred.The inoculation was performed on solid media (glucose agar), the Petri plates were incubated at $37^{\circ} \mathrm{C}$ for the first day, and then maintained at laboratory temperature for the following days. After primary isolation on the glucose agar medium, passages were made

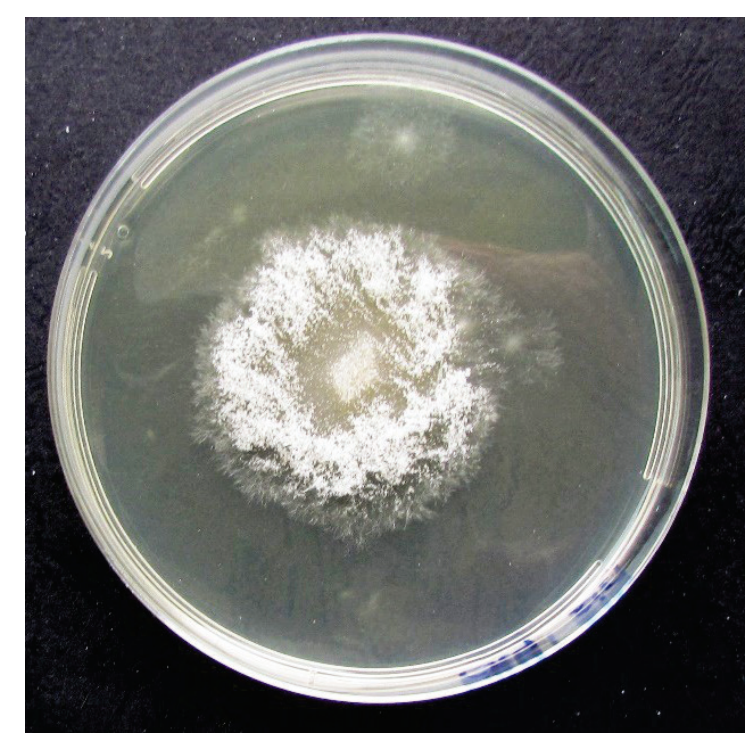

Figure 1. Colony on glucose agar at $24 \mathrm{~h}$ on the following media: Sabouraud agar, CLED agar (cysteine, lactose, electrolyte deficient) (Oxoid), egg yolk agar, Mac Conkey agar with sorbitol (Becton Dickinson), slant glucose agar. All the inoculated media were incubated at $37^{\circ} \mathrm{C}$ for the first 24 hours, and then maintained at laboratory temperature for the following days.To test antifungal sensitivity, the Multidisc system was used (YEASTS $®$ Liofilchem, Italy), containing the following antifungals: Econazole $10 \mu \mathrm{g}(\mathrm{ECN})$, Nystatin 100 I.U. (NY), Griseofulvin $10 \mu \mathrm{g}$ (GF), Amphotericin $20 \mu \mathrm{g}$ (AMB), Flucytosine $1 \mu \mathrm{g}$ (FY), Miconazole $10 \mu \mathrm{g}$ (MCL), Metronidazole $10 \mu \mathrm{g}$ (MTZ), Ketoconazole $10 \mu \mathrm{g}$ (KCA).

Measurement of the inhibition areas was performed with a digital micrometer.Antifungals considered ineffective did not induce a halo.

\section{Results and discussions}

Cultural aspects. Primary inoculation was performed on the glucose agar medium as a spot in the center of the plate.After 24 hours, we noticed the development of a $\sim 6 \mathrm{~cm}$ white cotton-like colony.On all used culture media, rapid growth was observed, the culture having a tendency to spread on almost the entire surface of the plate within 36-48 hours.During this time, on the magnifying glass examinations the mycelium is white in color, the hyphae having the appearance of fine aerial filaments (Figure 1 and Figure 2).

Examination in the following days shows an increase in mycelial density over the entire

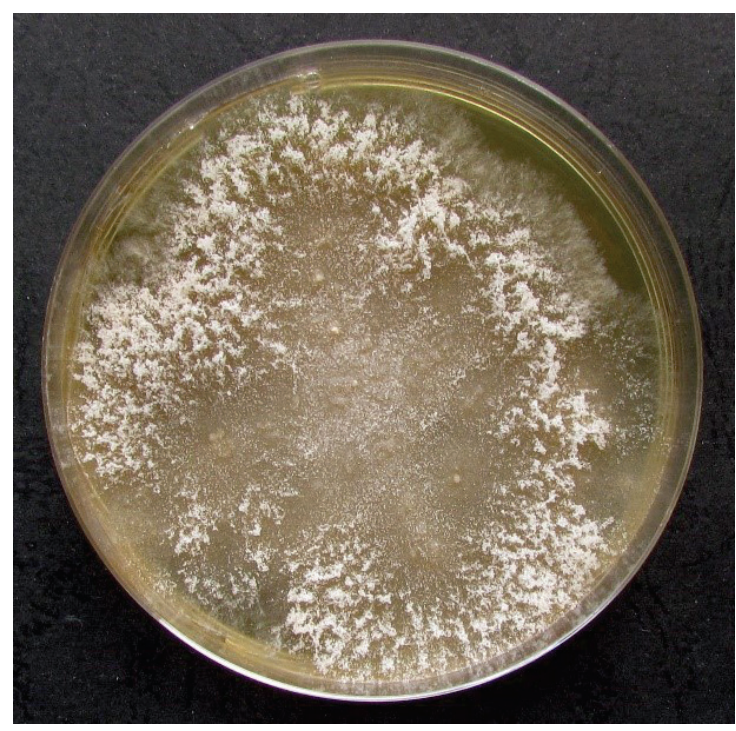

Figure 2. Culture on Sabouraud mediumat $48 \mathrm{~h}$ 


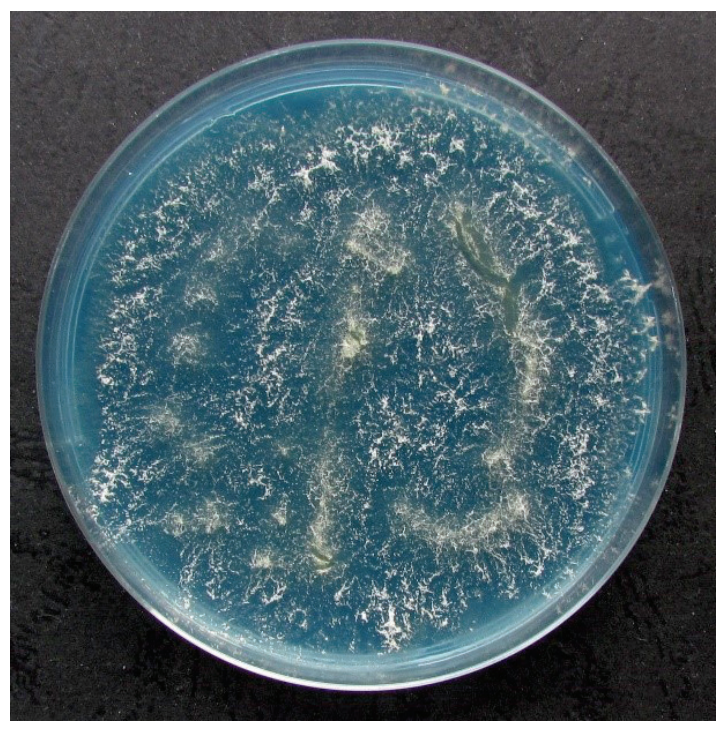

Figure 3. Culture onCLEDmedium at $24 \mathrm{~h}$

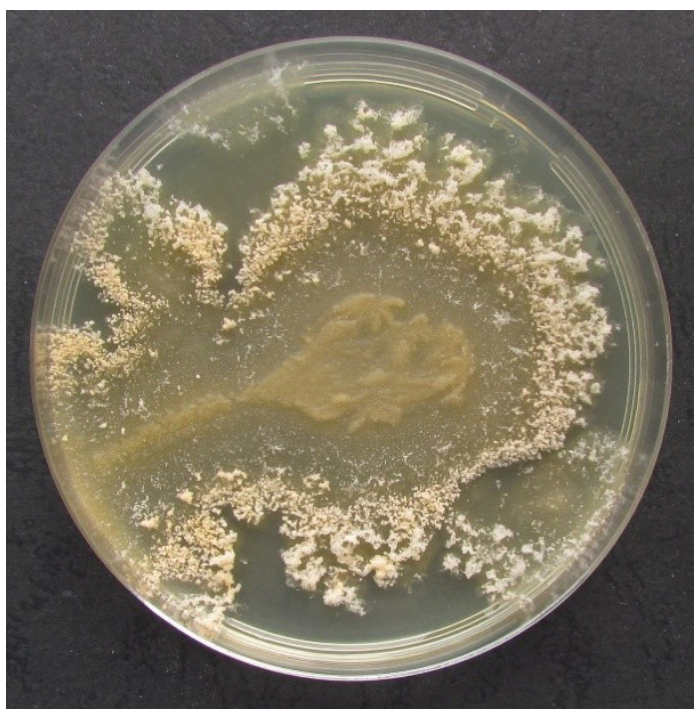

Figure 5. Culture on CLED medium at 7 days

surface, with an agglomeration at the periphery of the plate and climbing trend over the wall (Figure 3 and Figure 4). At 48-72 hours, in the crowded areas, the mycelium gets a pale pink/ orange color.A week later, there was an abundant increase in the marginal area of the plates, and the accentuation of the orange color (CLED medium) (Figure 5), as well as an aspect of coalescence in the central area (glucose agar medium), where hyphae can no longer be distinguished (Figure 6).

In the agar slant, at 24 hours, the same rapid growth pattern was found, the mycelium tending to extend over the entire surface.At 48-72 hours, the culture became denser, and there was a more

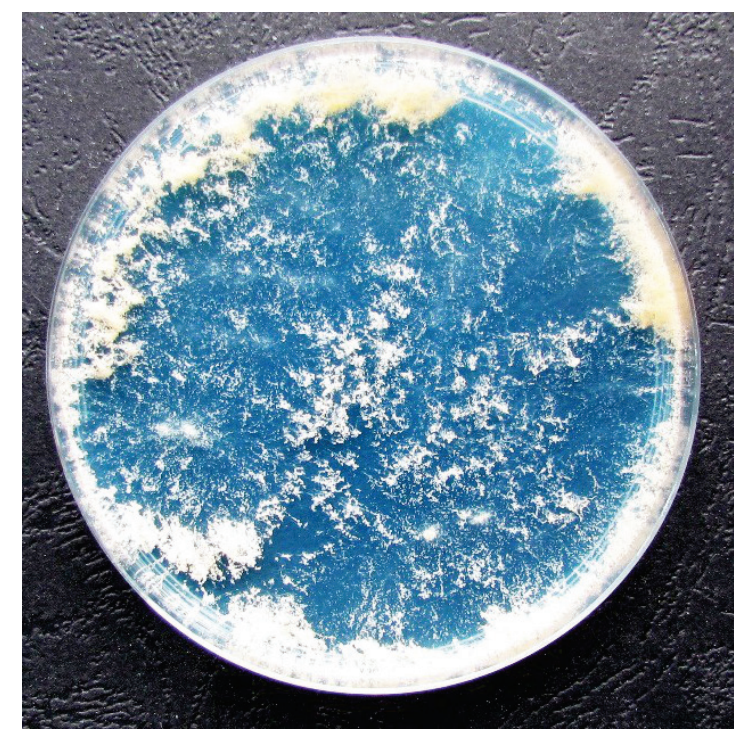

Figure 4. Culture on CLED medium at $48 \mathrm{~h}$

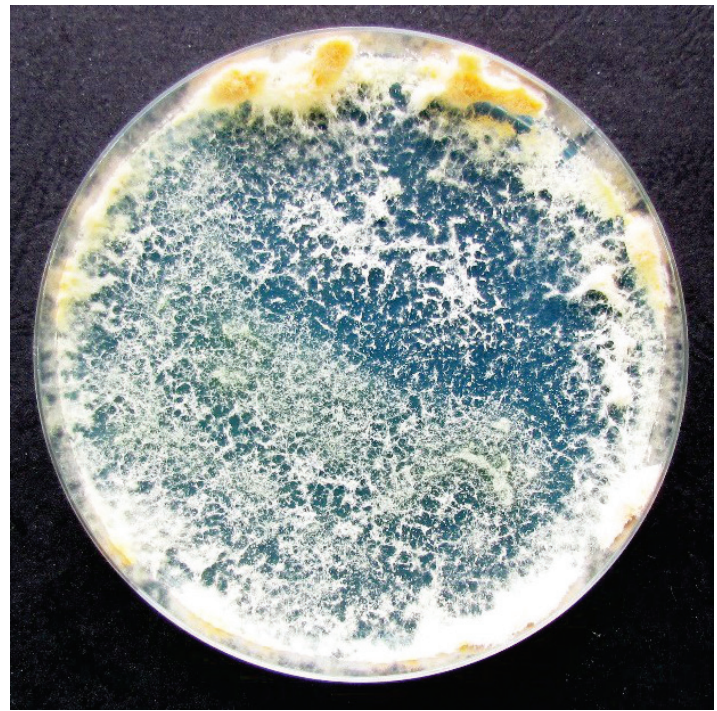

Figure 6. Culture on glucose agar at 7 days

abundant development in the upper area of the slant agar, where the density was higher, the mycelium getting a slightly pink color (Figure 7 a, b, c). Of the culture media used, we estimate that the fastest growth occurred on the Sabouraud medium, but good growth was also achieved on other media (glucose agar, CLED medium, egg yolk medium). We mention the lack of growth on Mac Conkey agar with sorbitol.

Morphological aspects. From the culture developed on the surface of solid media smears were performed using Lugol's solution and methylene blue, and then covered with a coverslip. 


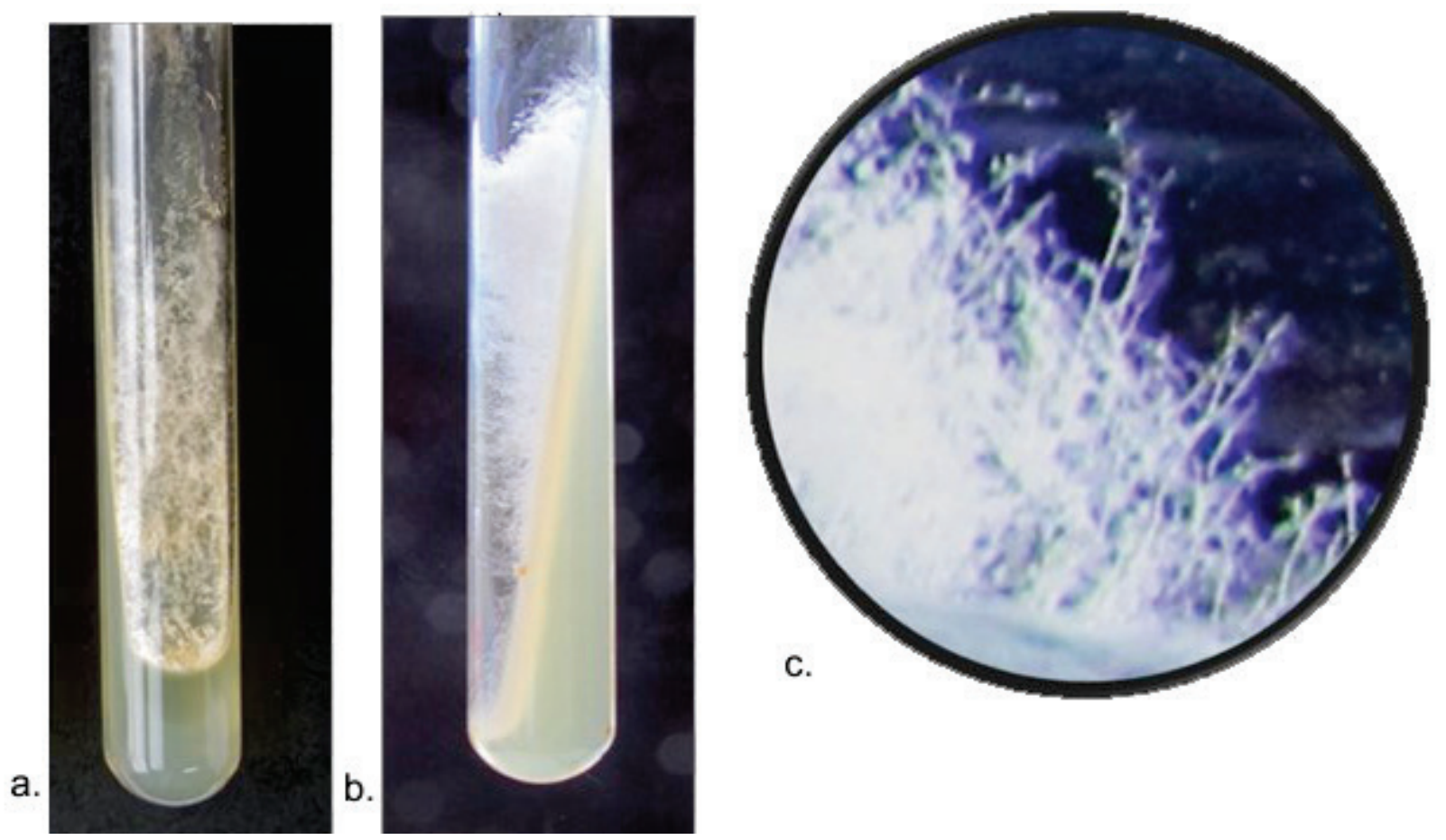

Figure 7. Slant agar culture

a) at $24 \mathrm{~h} \mathrm{~b}$ ) at $72 \mathrm{~h} \mathrm{c}$ ) hyphae appearance (detail)

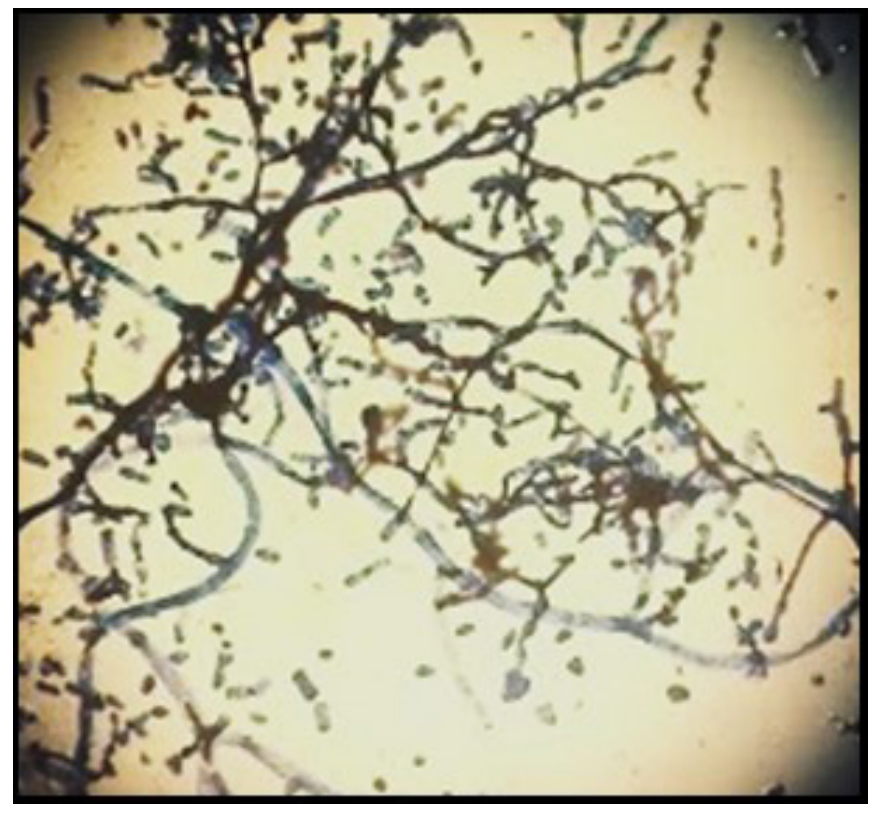

Figure 8. Septate hyphae, chains of conidia, free spores (magnification x 4)

The examination revealed braided septate hyphae, with smooth hyaline walls, from which simple or branched conidiophores were formed, with oval conid chains and numerous free spores (Figure 8).
Susceptibility to antifungals. The isolated strain was found to be sensitive to ketoconazole (KCA), econazole (ECN), miconazole (MCL) with inhibition areas exceeding $30 \mathrm{~mm}$;less sensitive to amphotericin B, with a $24 \mathrm{~mm}$ inhibition area 


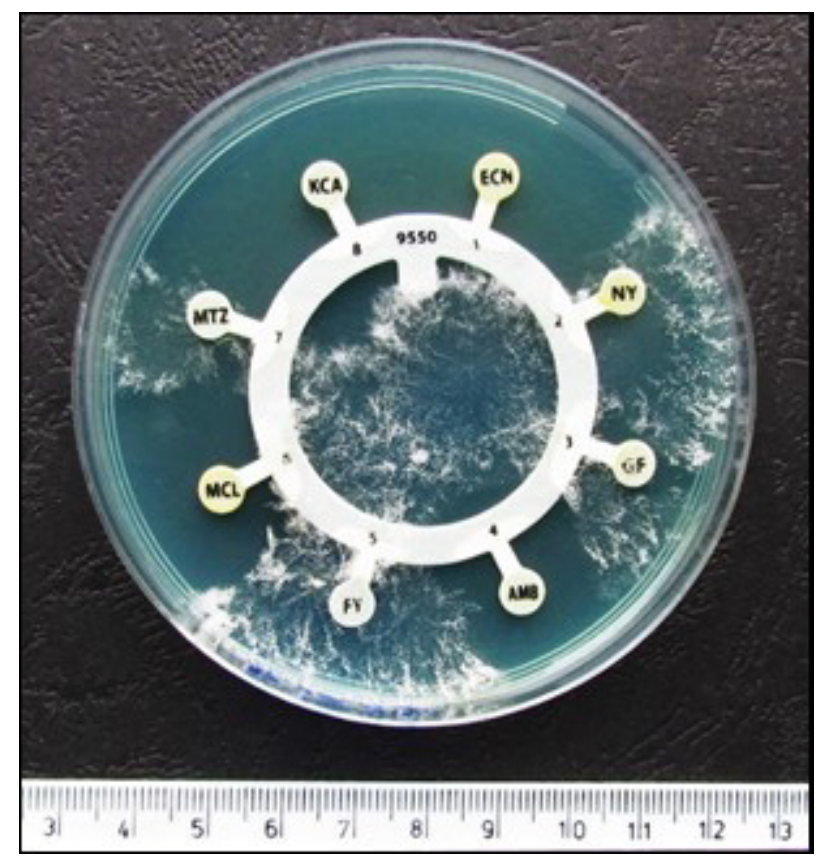

Figure 9. Aspects of inhibition zones, CLED medium (Multidisc YEASTS®, Liofilchem)

and showed resistance to metronidazole (MTZ), nystatin (NY), griseofulvin (GF) and flucytosine (FY) (Figure 9).

In the event of a therapeutic intervention, these antifungal agents (ketoconazole, econazole or miconazole) may be recommended for medical applications.In the literature we did not find data that would give a pattern of susceptibility to different antifungal groups, so we cannot compare the results with other researches.

Fungal infections, especially those caused by opportunistic species, have become substantially more frequent in recent years, with potentially significant economic consequences and serious implications for public health (especially for individuals with different forms of immunosuppression).Chrysonilia sitophila, known as the red mold of bread, is the most widespread species in the outside environment, from where it can reach various foods (bread, bakery, fruit and meat) (Patel Sunil, 2008), and even dialysis drugs (Febre et al., 1999). It can be a problem for bakeries when it contaminates them, being difficult to eradicate (Berni et Scaramuzza, 2013). It is noted that ethanol can be an effective barrier to prevent damage to bread and pastry products caused by some fungi such as Chrysonilia sitophila and Hyphopichiaburtoni, whose growth is inhibited at very low concentrations $(0.8 \%$ and 2.0\%, respectively) (Berni et Scaramuzza, 2013).

Room contamination is also a serious problem for microbiology laboratories, being difficult to combat once it spreads in them (Pitt et Hotckin). It is considered to be a pathogen-free contaminant and is unlikely to produce toxic metabolites (Pitt et Hotckin, 2012). However, Chrysonilia sitophila is recognized as a source of allergens, inducing disease predisposition to people working in highly contaminated environments (food industry and wood industry) causing occupational diseases (Tarlo et al., 1996; Monzón et al., 2009). There is reported involvement in the production of asthmatic disease with respiratory and ophthalmic symptoms in a worker who maintained coffee dispensers, stating that the inhaled coffee powder was coated with a pink/orange fine layer in which C. sitophilait was identified (Francuz et al., 2010). To determine the involvement of $C$. sitophila in the induction of sensitization, commercial extracts used in allergic testing were prepared (21). It poses a major risk to health, in the case of lesioning of anatomical barriers (corneal perforation, major surgery), or the application of catheters, the injection of contaminated drugs, etc (20). It may have implications in peritonitis production if dialysis fluids are contaminated with fungi, 
Chrysonilia sitophila and Chaetomiumglobosum being mentioned (Febré et al., 1999). Beneficial effects are also mentioned, namely applications in various biotechnologies and winemaking, especially for the protection of corks, having the ability to inhibit the development of other fungi (Pereira et al., 2000). Research has proven the potential of mold to metabolize suberin, the main components of cork cells(the main function of suberin is to act as a barrier for movement of water and solutes (Vitorino et al., 2007). It has been shown to produce lignin peroxidase, an enzyme that is used in decontamination of kraft effluents (De Alka Dwevedi). It has also been demonstrated, in vitro, that it has the ability to degrade polycyclic aromatic hydrocarbons (Gofar, 2011). A strain of $C$. sitophila has been shown to be useful in the production of $\beta$-fructofuranosidase, using various agro-food residues (Pratil et al., 2011). C. sitophila is incriminated in the pink pigmentation of the swan feather (Cygmusolor), the feathers become brittle, fragmented and lose the ability to reject water. This phenomenon was observed only in swan's dependent on artificial, hypertrophic feed (which may be a favorable environment for the development of fungi) and was not found in swans feeding on aquatic vegetation.It is noted that Chrysonilia sitophila is isolated from the affected feathers, and the HPCL has demonstrated the carotenoid nature of the pigment. (O'Connell et al., 2011).

The isolated strain described in this paper corresponded (morphologically and culturally) to those detailed in the consulted medical literature. For identification, rapid growth in solid culture media, the tendency to spread within 48-72 hours over the entire surface of the medium, and the coloration of mycelium in pink / orange are important.To avoid spreading in the environment, especially under laboratory conditions, it is recommended to perform inoculations in leakproof agar tubes (agar slants) and not in Petri dishes, from which it can easily spread.

Although the pathological significance is uncertain and still under discussion, it is quite often isolated from workers' nostrils, from corkscrew factories, being known that this industry is related to high dust contamination that will promote the exposure to fungi (Viegas et al., 2015).

\section{Conclusion}

The results obtained are an important point of reference, as the data on the sensitivity of $C$. sitophila to azole are non-existent.

In a possible therapeutic need, these antifungal agents, to which Chrysonilia is susceptible, may be used as a treatment.

Acknowledgments. This research did not receive any specific grant from funding agencies in the public, commercial, or not-for-profit sectors.

\section{References}

1. Berni E, Scaramuzza N (2013). Effect of ethanol on growth of Chrysonilia sitophila (the red bread mould) and Hyphopichiaburtonii(the chalky mould) in sliced bread. Lett. Appl. Microbiol., 57(4): 344-349.

2. De Alka Dwevedi (2016). Enzyme Immobilization. Advances Industry, Agriculture, Medicine, and the Environment.Imobilization Enzyme in Waste Water Treatmentp. 91-92.

3. Febré N, Silva V, Medeiroa EAS, Godoy P, Reyes E, Halker E, Fischman $O$ (1999). Contamination of peritoneal dialysis fluid by filamentous fungi. Rev. Iberoam. Micol., 16:238239.

4. Francuz B, Year H, Geraut L, Bensefa-Colas L, Nghiem ZH, Choudat D (2010). Occupational Asthma Induced by Chrysonilia sitophila in a Worker Exposed to Coffee Grounds. Clin. Vaccine Immunol., 17(10):1645-1646.

5. Gofar N (2011). Characterization of petroleum hydrocarbon decomposing fungi isolated from mangrove risosphere. J. Trop. Soils, 16(1):39-45.

6. Monzon S, Gil J, Ledesma A, Ferrer L, San Juan S, Abos $\mathrm{T}$ (2009). Occupational asthma IgE mediated due to Chrysonilia sitophila in coffee industry. Allergy, 64(11)

7. O'Connell MM, Keating U, Mcelligott D, O'Reilly $P$, O'Callaghan J, O'Halloran J (2011). An Investigation of a novel anormalous pink feather colouration in the Mute Swan Cygnus olorin Britain and Ireland. Wildfowl., 61:152-165.

8. Pereira CS, Pires A, Valle MJ, Figueiredo Marques JJ, San Romao MV (2000). Role of the Chrysonilia sitophila in the quality of cork stoppers for sealing wine bottles. J. Ind. Microbiol. Biotechnol., 24: 261-266.

9. Perkins DD, Davis RH (2000). Evidence for Safety of Neurospora Species for Academic and Commercial Uses. Applied and Environmental Microbiology, 66(12):51075109.

10. Pitt IJ, Hocking AD (2012). Fungi and Food Spoilage; Springer US, p. 86-87.

11. Pratil PR, Reddy GSN, Sulochana MB (2011). Production, optimization and characterization of $\beta$-fructofuranosidase by Chrysonilia sitophila PSSF84-A novel source. Indian Journal of Biotechnology, 10: 56-64.

12. Patel Sunil (2008).Ilustrated Dictionary of Mycorbiology, p. 125 
13. Tarlo Susan M., Wei Yvonne, Dolovich J., Summerbel R.(1996).Ocupational asthma induced by Chrysonilia sitophila in the logging industry. Allery Clin. Immunol., 97: 1409-13.

14. Theodore FH, Littman ML, Almeda E (1962). Endophthalmitis following cataract extraction. J Ophthalmol., 53:35-39.

15. Thomas PA, Kaliamurthy J (2013). Mycotic keratitis: Epidemiology, diagnosis and management. Clinical Microbiology and Infection, 19 (3):210-220.

16. Viegas C, Clérigo A, Faria T, Sabino RFP, Verissimo C, Quintal Gomes A, Viegas S (2015). Accessing occupational exposure to fungi in a cork industry. Mycoses, 58(Suppl. 4):140. Abstracts
17. Vitorino SI, Neves ESG, Gaspar F, Figueiredo Marques JJ, San Ramao MV (2007).Suberin utilization by Chrysonilia sitophila: evidence for lipolytic enzymes production. Ciência Tec, Vitiv., 22(1): 1-4.

18. von Arx JA (1981). On Monilia sitophila and some Families of Ascomycetes. Sydowia, XXXIV: 13-29.

19. *** Chrisonilia sitophila. www.thunderhouse4-yuri. blogspot.ro/

20. *** Chrysonilia. www.moldbacteria.cm/

21. ${ }^{* * *}$ Chrisonilia sitophila. www.drugbanck.ca/

22. *** Taxonomy of Allergenic Fungi. The Journal of Allergy and Clinical Immunology: in Practice. www.jaci -in practice.org/ 